\title{
Extraction of Dwellings of Displaced Persons from VHR Radar Imagery - A Review on Current Challenges and Future Perspectives
}

\author{
Andreas Braun 12 \\ 1 Paris Lodron University of Salzburg, Austria \\ 2 University of Tübingen, Germany
}

\begin{abstract}
While many studies exist to identify buildings from optical satellite images, radar-based approaches are still lacking in humanitarian contexts. This article outlines the main challenges related to scattering mechanisms returning from huts, tents, informal dwellings, and their natural surroundings, but also from geometric distortions caused by the sidelooking radar aperture. An outlook summarizes how these limitations can be overcome by image enhancement or multi-image composites, but also by advanced methods on building extraction, such as convolutional neural networks (CNNs). This article aims to stimulate scientific debate and to lay a foundation for the development of new methods.
\end{abstract}

Keywords: synthetic aperture radar (SAR), earth observation, humanitarian aid, building extraction

\section{Introduction}

Satellite images are increasingly used in humanitarian work. They effectively deliver consistent and accurate information over large areas, especially when they are remote or dangerous. Images help to allocate and count displaced persons, monitor natural resources and environmental changes, and therefore support the planning of missions, the distribution of goods and services, and the protection of people in need (Lang et al., 2020). Radar images are especially helpful in this context because they map physical surface characteristics independently from cloud cover, therefore, allowing quick response to emergencies (Boccardo et al., 2015). Their use for humanitarian action has been demonstrated in various cases, for example, for mapping settlements or identifying natural resources and hazards (Braun, 2020). However, while numerous approaches exist using very high resolution (VHR) optical imagery, radar-based studies are rare, particularly in the detection of dwellings as a crucial information for humanitarian work. This article discusses the reasons for this research gap and outlines how this issue can be addressed in the future. Furthermore, it provides examples on the interaction of microwaves with informal settlements to provide a basic understanding necessary for the design and conduction of studies in this domain. 


\section{Current limitations}

\subsection{Spatial resolution}

One reason for the scarcity of radar studies on building extraction is the low availability of VHR radar images. Compared to optical satellites with sub-meter resolutions which have operated since the beginning of the 21st century, the development of VHR SAR satellites shows a delay of 10-20 years which, of course, also affects the methodological development. Among the small number of existing studies on building extraction from single VHR SAR images, sufficient results were only achieved for medium-size and large buildings with regular shapes (Ferro et al., 2012). Studies on small and irregular buildings are still missing. As a foundation for future studies, Table 1 lists the currently available radar data operating at very high spatial resolution.

Table 1: Selection of suitable SAR missions for dwelling detection

\begin{tabular}{|l|r|r|l|}
\hline Sensor / Image Mode & $\begin{array}{l}\text { Azimuth } \\
\text { resolution }\end{array}$ & $\begin{array}{l}\text { Range } \\
\text { resolution }\end{array}$ & Availability \\
\hline TerraSAR-X / HighRes Spotlight & $0.6 \mathrm{~m}$ & $1.1 \mathrm{~m}$ & 2007 - today \\
\hline Radarsat-2 / Spotlight & $0.8 \mathrm{~m}$ & $1.6 \mathrm{~m}$ & 2008 - today \\
\hline TerraSAR-X / Staring Spotlight & $0.24 \mathrm{~m}$ & $0.6 \mathrm{~m}$ & $2013-$ today \\
\hline COSMO SkyMed / Spotlight & $0.9 \mathrm{~m}$ & $1.0 \mathrm{~m}$ & $2014-$ today \\
\hline RISAT-1 / HighResolution & $1.0 \mathrm{~m}$ & $0.67 \mathrm{~m}$ & $2012-2017$ \\
\hline Kompsat-5 / Ultra HighResolution & $0.85 \mathrm{~m}$ & $<0.85 \mathrm{~m}$ & $2015-$ today \\
\hline COSMO SkyMed SG / Spotlight 2A & $0.35 \mathrm{~m}$ & $0.55 \mathrm{~m}$ & $2020-$ today \\
\hline ICEYE / Spotlight & $0.5 \mathrm{~m}$ & $0.5 \mathrm{~m}$ & $2020-$ today \\
\hline ICEYE / Spotlight High & $0.25 \mathrm{~m}$ & $0.5 \mathrm{~m}$ & $2020-$ today \\
\hline Capella / Site & $0.5 \mathrm{~m}$ & $1.0 \mathrm{~m}$ & $2021-$ today \\
\hline Hisea-1 / Spotlight & $<1.0 \mathrm{~m}$ & $1.0 \mathrm{~m}$ & $2021-$ today \\
\hline Capella / Spot & $0.4 \mathrm{~m}$ & $0.6 \mathrm{~m}$ & planned for 2022 \\
\hline Umbra / Staring Spotlight & $0.25 \mathrm{~m}$ & $0.25 \mathrm{~cm}$ & planned for 2022 \\
\hline XpressSAR / Spotlight & $<1.0 \mathrm{~m}$ & $<1.0 \mathrm{~m}$ & planned for 2024 \\
\hline
\end{tabular}

\subsection{Information content}

Radar images are formed by microwaves of several centimetres length. This makes them sensitive to physical characteristics (roughness, moisture, material, shape and orientation) of surfaces and objects (Ulaby et al., 2019). A systematic comparison of how buildings of different materials react to radar waves is provided in Figure 1. As shown by the TerraSAR-X (Spotlight) image in Figure 1b, the buildings of Goz Beïda (Chad) produce high radar backscatter, mainly because of the corner reflection of signals from buildings. However, high returns are also received by trees in the eastern part (volume scattering) and wetlands in the north (specular scattering). The identification of buildings by high radar backscatter from single images is therefore a challenge. Besides the ambiguity of the radar signal, a significant limitation in humanitarian settings is the material of the buildings. 

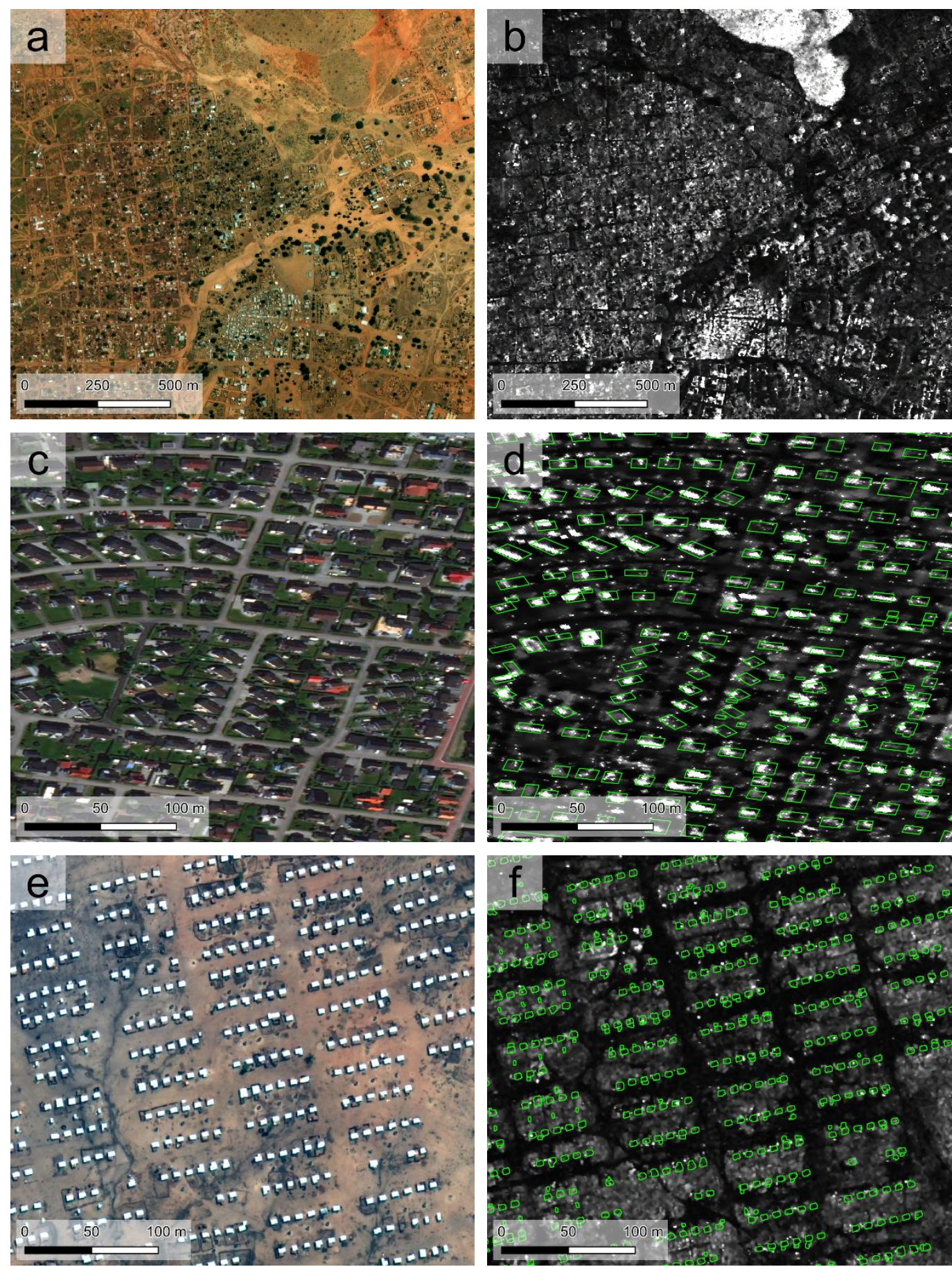

Figure 1: Goz Beïda (a, b), Lilleström (c, d) and Minawao (e, f) in VHR optical and radar images. Green outlines indicate building footprints retrieved from the optical image. TerraSAR-X @ DLR 2021 
Buildings covered by natural materials (straw on tukuls), or fabric or canvas (tents) produce distinctively less backscatter than solid clay or metal roof tiles. While solid buildings in the city of Lillestrøm (Norway) are characterized by locally high backscatter in Figure 1d, the regularly arranged tents in the refugee camp of Minawao (Cameroon) are mostly penetrated by the radar signal (Figure 1f) and therefore produce no backscatter. These low signals are often even superimposed by volume scattering of hedges or shrubs, which are used in arid regions to separate households in refugee camps, as demonstrated in Figure 2a showing the refugee camp of Dagahaley (Kenya). Accordingly, the potential of radar data often depends on the type of dwellings and their materials which can range from textile or natural materials (low visibility)to all kinds of solid coverage (higher visibility) in refugee camps or informal settlements.

Lastly, due to interference of different signal returns, radar images are characterized by speckle: a granular pattern (Figure 2b and Figure 5) which complicates both visual interpretation and the automated extraction of information (Lee et al., 1994). It can be partially mitigated by adaptive filters, as demonstrated in section 3.2.
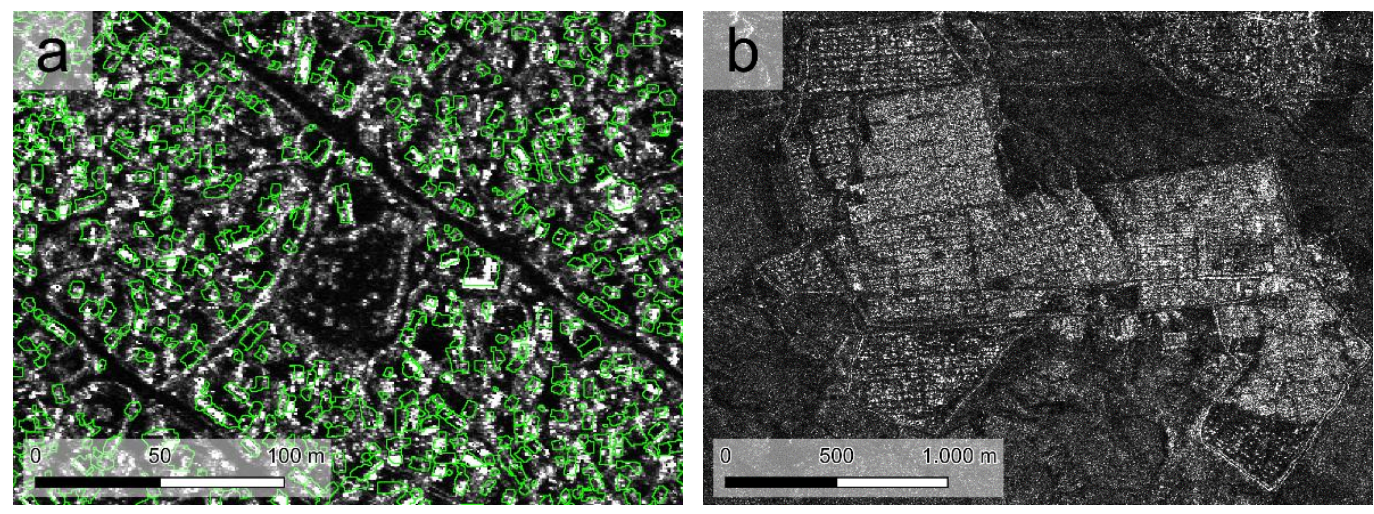

Figure 2: Volume scattering in a TerraSAR-X image of Dagahaley (a), and speckle in an unfiltered ICEYE image of Al Hol (b). TerraSAR-X @ DLR 2021

\subsection{Acquisition geometry}

The active nature of a radar sensor requires a side-looking geometry of the satellite, resulting in incidence angles between 25 and 45 degrees. This introduces several geometric and radiometric distortions in the image, which require careful pre-processing (Oliver et al., 2004). Most of them can be compensated by the integration digital elevation model. However, with increasing spatial resolutions, freely available DEMs are no longer sufficient, especially for reducing signal saturation at slopes facing towards the sensor (Figure 3a). Besides these topographic effects, the orientation of buildings combined the flight and look direction of the radar sensor has a considerable impact on their backscatter intensity. As shown in Figure 3b, even solid administrative buildings in camp Minawao (Cameroon) are only visible as a thin line because the incoming microwave is reflected by just one wall. This brings new challenges regarding the delineation of building footprints. 

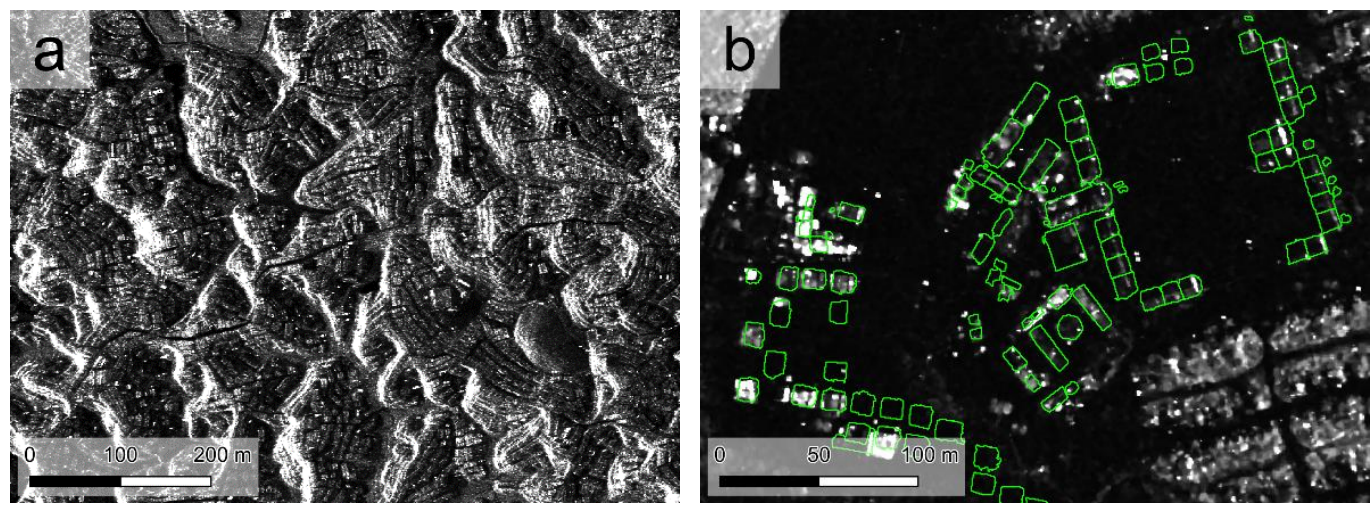

Figure 3: Geometric effects in radar images of Kutupalong (a) and Minawao (b). TerraSAR-X @ DLR 2021

\section{Solutions and future developments}

\subsection{Using proxy measures}

The previous examples have shown that some types of dwellings do not produce a distinct backscatter signal which can be used to allocate them, for instance because of their material, their orientation, or their size. When the spatial resolution is not sufficient to delineate single buildings, one alternative is dwelling density. The relationship between dwelling density and backscatter intensity has been investigated and utilized in studies for Dagahaley (Figure 4; Braun, 2020) and Maiduguri (Lang et al., 2020). Combined with knowledge of household sizes, these approximations can then be used to estimate the number of residents. However, this requires collecting reference statistics on household sizes in the field and is not a precise method for subtle changes within informal settlements.
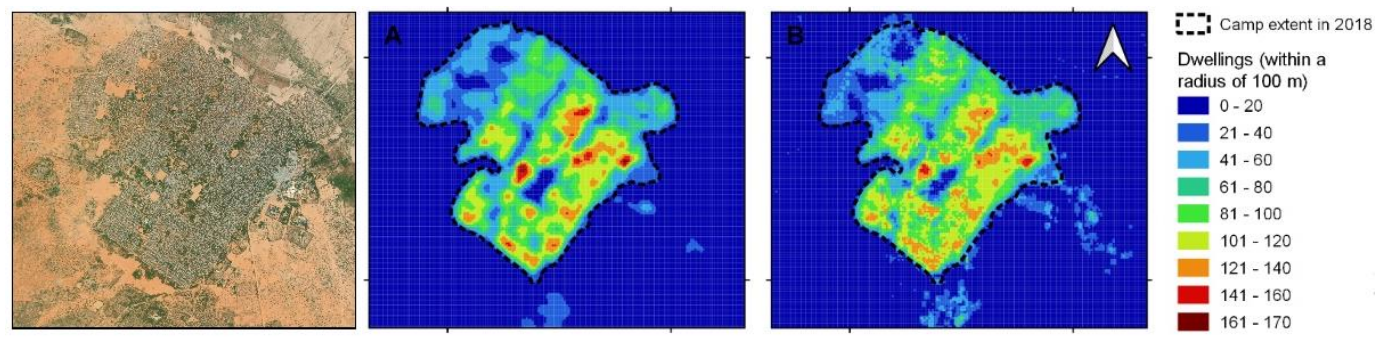

Figure 4: Observed (A) and predicted (B) dwelling density of camp Dagahely (Braun, 2020)

\subsection{Image enhancement}

While most speckle filters were designed for SAR satellites such as ERS, ENVISAT or ALOS, they approach speckle at pixel resolutions between 10 and 30 meters. Accordingly, they are not entirely suitable to address patterns within VHR data, because the concept of a moving 
window with the size of a few pixels is not applicable at this scale. For these VHR products, filters based on region-growing algorithms, such as the intensity-driven adaptiveneighborhood (IDAN) filter (Vasile et al., 2006), have proven to be more effective because they suppress speckle while keeping the outlines of very bright pixels sharp. This is illustrated in Figure 5 (top): While traditional filters, such as Lee Sigma, Frost or Boxcar struggle with locally high values, the region-growing IDAN filter preserves the outlines of the building while smoothing its surroundings. Still, more filter techniques adapted to very high resolutions have to be developed.

Another way of increasing the quality of a radar image is to combine images from multipe dates using temporal averaging of the backscatter intensity. As shown in Figure 5 (bottom), a single scene can contain a large proportion of random signal contributions. A clearer image is produced by increasing number of images, these are systematically suppressed. However, this requires a large number of images, preferably within a short time frame. Therefore, this approach is not ultimately applicable in cases of emergencies where no archived images exist.
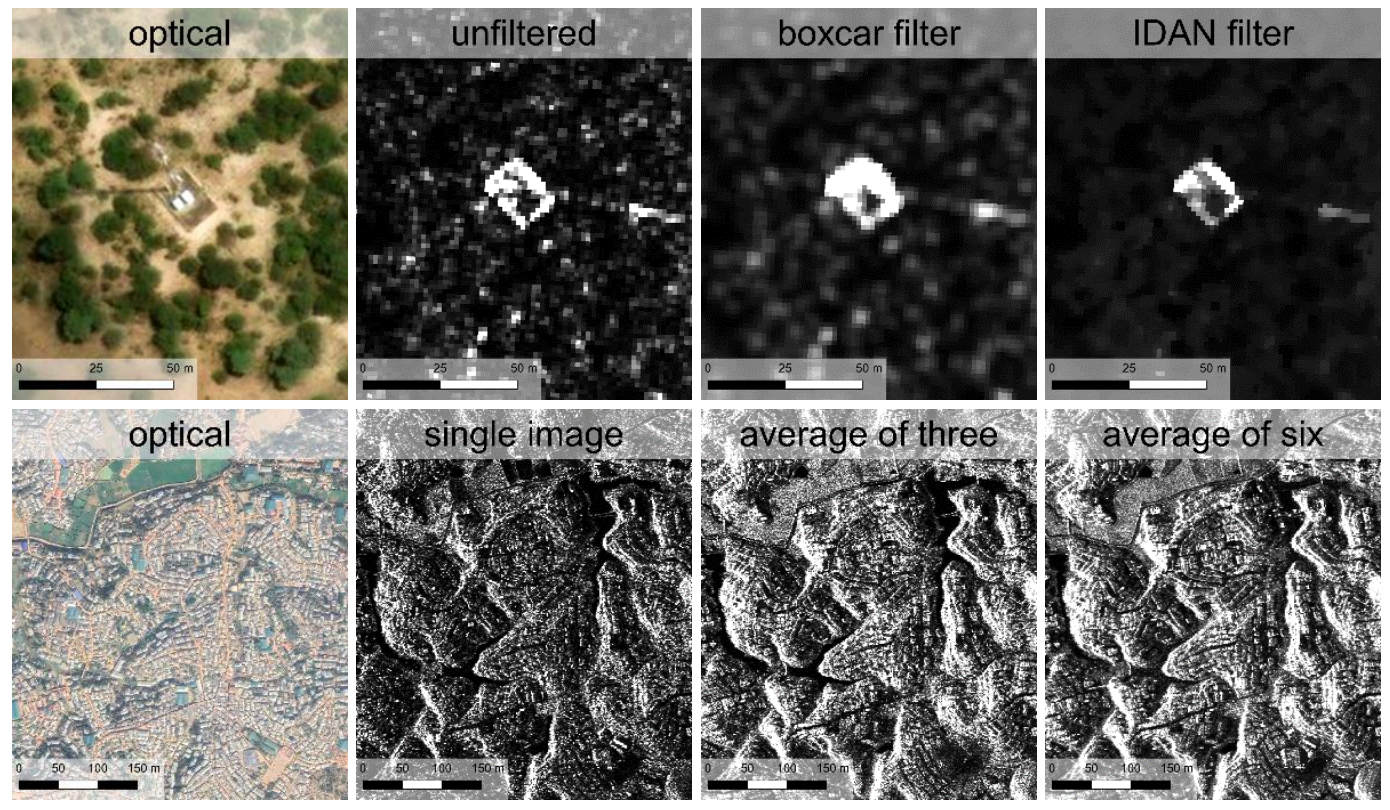

Figure 5: Top: Effect of different filters on a single dwelling in Namibia. Bottom: Effect of image averaging on TerraSAR-X (C) DLR 2021

Lastly, little backscatter of buildings made of light construction materials can be mitigated by a fusion of VHR optical and radar images, for example, as demonstrated by Spröhnle et al. (2017), who systematically compared the information content of WorldView-2 and TerraSAR$\mathrm{X}$ Spotlight products for the extraction of dwellings in the Al Zaatari refugee camp (Jordan). They confirm that only metal buildings can be reliably identified in radar images, nevertheless, reporting that the fusion of both sensors brings the highest accuracy. A benchmark dataset for the systematic evaluation of approaches based on optical and radar imagery in urban areas 
(SARptical) is provided by Wang and Zhu (2019). On the downside, fusion methods increase the dependency of users from several product sources, which unfortunately is counterproductive in emergencies.

\subsection{Advanced approaches}

As shown in the previous chapters, traditional pixel-based methods fail to reliably identify buildings of displaced persons because of insufficient spatial resolution, little backscatter intensity compared to their surroundings, and geometric effects on building and landscape levels. For this reason, advanced methods which aggregate pixels to segments or semantic objects can be used. Object-based image analysis (OBIA) has already been applied in urban areas using VHR radar imagery, but primarily for change detection based on multi-temporal approaches and not identifying dwellings from single images (Pirrone et al., 2020). One key to successfully identifying dwellings is the understanding and exploitation of typical patterns of double-bounce and signal shadow caused by solid buildings and how these relate to the actual footprint (Soergel, 2010). Once more, this is complicated by partial lacking of backscatter from buildings containing natural construction materials. Advancements in machine learning or pattern recognition, particularly in the training and application of convolutional neural networks (CNN), an help overcome these gaps. Nonetheless, they do currently struggle with the asymmetric dynamic range of the radar signals in urban areas, hich require suitable histogram normalization (Zhu et al., 2020). Lastly, the integration of phase information can greately enhance the quality of urban footprinz delineation, for example, by methods of SAR tomography (Wang \& Zhu, 2019). Nevertheless, these require large numbers of systematic image acquisitions and are currently not tested for rural areas.

\section{Discussion and outlook}

Concludingly, the development of radar-based approaches for the identification of buildings for humanitarian purposes still faces many challenges. Predominantly, the variety of different settings brings difficulties for the creation of both accurate and transferable methods, which can then be used in operational settings with low dependencies on specific sensors, acquisition geometries, or extensive data preparation. Future SAR missions will bring new opportunities for spatial resolution and data quality (Table 1), especially in combination with advancements in Deep Learning. Methods adapted to buildings of light construction materials and rural settlements still have to be developed. However, these will still require a sufficient number of input images (SAR only or combined with optical data) and training samples, for example, from previous dwelling extractions. Finally, the availability of in-situ information is crucial for developing methods contributing to both the calibration of models and the validation of generated results. As areas of interest can be hard or even dangerous to access, this is only possible in close collaboration with humanitarian organizations depolyed in such regions. To grant results with an accuracy sufficient for humanitarian decision making, the development of approaches should, therefore initially, focus on specific sites or settings instead of aiming at universally transferable methods. 
Braun

\section{Acknowledgements}

This study was funded by the Christian Doppler Forschungsgesellschaft within the Christial Doppler Laboratory for Earth Observation for Humanitarian Action (CDL GEOHUM).

\section{References}

Boccardo, P.Tonolo, F. G. (2015). Remote sensing role in emergency mapping for disaster response. In G. Lollino, A. Manconi et al. (Eds.), Engineering Geology for Society and Territory (pp. 17-24). Cham: Springer. doi:10.1007/978-3-319-09048-1_3

Braun, A. (2020). Spaceborne radar imagery: An under-utilized source of information for humanitarian relief. Journal of Humanitarian Engineering, 8(1).

Ferro, A., Brunner, D.Bruzzone, L. (2012). Automatic detection and reconstruction of building radar footprints from single VHR SAR images. IEEE Transactions on Geoscience and Remote Sensing, 51(2), 935-952.

Lang, S., Füreder, P., Riedler, B., Wendt, L., Braun, A. et al. (2020). Earth observation tools and services to increase the effectiveness of humanitarian assistance. European Journal of Remote Sensing, 53(sup2), 67-85.

Lee, J. S., Jurkevich, L., Dewaele, P., Wambacq, P.Oosterlinck, A. (1994). Speckle filtering of synthetic aperture radar images: A review. Remote Sensing Reviews, 8(4), 313-340. doi:10.1080/02757259409532206

Oliver, C.Quegan, S. (2004). Understanding Synthetic Aperture Radar Images: SciTech Publishing.

Pirrone, D., Bovolo, F.Bruzzone, L. (2020). An Approach to Unsupervised Detection of Fully and Partially Destroyed Buildings in Multitemporal VHR SAR Images. IEEE Journal of Selected Topics in Applied Earth Observations and Remote Sensing, 13, 5938-5953. doi:10.1109/JSTARS.2020.3026838

Soergel, U. (2010). Review of radar remote sensing on urban areas. In U. Soergel (Ed.), Radar remote sensing of urban areas (pp. 1-47). Berlin: Springer.

Spröhnle, K., Fuchs, E.-M.Aravena Pelizari, P. (2017). Object-Based Analysis and Fusion of Optical and SAR Satellite Data for Dwelling Detection in Refugee Camps. IEEE Journal of Selected Topics in Applied Earth Observations and Remote Sensing, 10(5), 1780-1791. doi:10.1109/JSTARS.2017.2664982

Ulaby, F. T., Dobson, M. C.Álvarez-Pérez, J. L. (2019). Handbook of radar scattering statistics for terrain ([Revised and updated]). Artech House Remote Sensing Library. Norwood, MA: Artech House.

Vasile, G., Trouve, E., Lee, J.-S.Buzuloiu, V. (2006). Intensity-driven adaptive-neighborhood technique for polarimetric and interferometric SAR parameters estimation. IEEE Transactions on Geoscience and Remote Sensing, 44(6), 1609-1621. doi:10.1109/TGRS.2005.864142

Wang, Y.Zhu, X. X. (2019). The Challenge of Creating The Sarptical Dataset. In IGARSS 2019 (pp. 5714-5717). IEEE. doi:10.1109/IGARSS.2019.8899803

Zhu, X. X., Montazeri, S., Ali, M., Hua, Y., Wang, Y., Mou, L., . . Bamler, R. (2020, June 17). Deep Learning Meets SAR. URL: https://arxiv.org/pdf/2006.10027 